\title{
The Dark Side of the Moon: Impact of Moon Phases on Long-Term Survival, Mortality and Morbidity of Surgery for LUNG CANCER
}

\author{
A. Kuehnl1,2, M. Herzog ${ }^{1}$, M. Schmidt ${ }^{3}$, H.-M. Hornung1 1 , K.-W. Jauch ${ }^{1}$, R. A. Hatz ${ }^{1}$, C. Graeb ${ }^{1}$ \\ ${ }^{1}$ Department of Surgery, Klinikum Grosshadern, Ludwig-Maximilians-University, Munich, Germany \\ ${ }^{2}$ Clinic for Vascular Surgery, Klinikum rechts der Isar, Technische Universität München, Germany \\ ${ }^{3}$ Department of Medical Informatics, Biometry and Epidemiology, Ludwig-Maximilians-University, Munich, Germany
}

\begin{abstract}
Objective: Superstition is common and causes discomfiture or fear, especially in patients who have to undergo surgery for cancer. One superstition is, that moon phases influence surgical outcome. This study was performed to analyse lunar impact on the outcome following lung cancer surgery.

Methods: 2411 patients underwent pulmonary resection for lung cancer in the past 30 years at our institution. Intra- and postoperative complications as well as long-term follow-up data were entered in our lungcancer database. Factors influencing mortality, morbidity and survival were analyzed.

Results: Rate of intra-operative complications as well as rate of post-operative morbidity and mortality was not significantly affected by moon phases. Furthermore, there was no significant impact of the lunar cycle on long-term survial.

Conclusion: In this study there was no evidence that outcome of surgery for lung cancer is affected by the moon. These results may help the physician to quite the mind of patients who are somewhat afraid of wrong timing of surgery with respect to the moon phases. However, patients who strongly believe in the impact of moon phase should be taken seriously and correct timing of operations should be conceded to them as long as key-date scheduling doesn't constrict evidence based treatment regimens.
\end{abstract}

Key words: Lung cancer, Superstition, Moon phases, Survival, Surgical complications

Abbreviations: $\mathrm{CI}=$ Confidence interval, $\chi^{2}=$ Chisquare test, $\mathrm{LOC}=$ Locus of control

\section{INTRODUCTION}

Superstition is very common, especially in some rural areas where nearly one-fifth of the population believes in the impact of moon phases on various phenomena and, among other things, outcome of medical treatment [1-3]. These patients may be anxious, especially when they have to undergo surgery for cancer [4]. The rationale for these anticipated effects have been credited to variations in the brightness of moon- light, weather conditions, geomagnetic variations as well as interstellar solar corpuscular radiation $[5,6]$. "Why should the moon, which causes the tides, doesn't influence human beings, who consist predominantly of water?" is a common believe. Consequently, many patients are essentially afraid of wrong timing of surgery with respect to moon phases, which might manipulate nurses and surgeons $[3,7]$. Thus, the impact of lunar cycles on treatment related complications, postoperative mortality and morbidity as well as long-term survival has been widely discussed by television shows, lay press and newsgroups in the internet. Several scientific studies have reported on the influence of moon phases on birth rates, birth complications, suicide, psychiatric crises, or outcome of surgery for breast cancer [4]. Since some studies underline significant influence of moon phases on human life [5, 8-11], other reports have failed to confirm these results $[2,4,12,13]$. It is well known, that physiological processes of the organism, i.e. the endocrine system, the autonomic nerve system, the liberation of growth factors or the limbic system are influenced by the moon cycle [4]. In addition, it is also postulated that significant impact of lunar phases is mediated by endogenous mechanisms [10]. In patients who have to undergo surgery for cancer, fear of operative complications and poor outcome is very widespread. In some cases, lunar phases are believed to be relevant for success of treatment. Therefore, this retrospective study was performed to analyse the influence of the moon phases on mortality, morbidity and long-term survival following lung cancer surgery at our institution.

\section{Patients And Methods}

We retrospectively reviewed the files of 2411 patients with complete long-term follow-up who received resective surgery for lung cancer between January 1980 and December 2007 at the Department of Surgery at our institution. The cohort included 1854 males and 557 females with a median age of $62.2 \pm 9.9$ years. Classification of tumor stages according to UICC 2002 was $41 \%, 21 \%, 21 \%, 6 \%$, and $11 \%$ for stadium I, II, IIIa, IIIb and IV, respectively. Type of surgery con- 
sisted pneumonectomies in $18 \%$, lobectomies and bilobectomies in $68 \%$, and lesser resections in $14 \%$ of all cases. The date of definitive surgery was allocated to the days of lunar cycle as well as to the dates of the four main lunar phases, that are new moon ( $\mathrm{n}=89$ ), waxing moon ( $\mathrm{n}=1058)$, full moon $(\mathrm{n}=77$ ) and waning moon $(\mathrm{n}=1187)$. Patients were grouped according to these four phases, as described by Moore and coworkers [14].

Patients long-term follow up was performed at our institution completed by data from the Munich Cancer Registry as well as updated by data from all GPs, community hospitals, chemoradiotherapy units and registration offices in Munich and its greater area. Median long-term follow-up was 25 months, ranging from 1 to 326 months.

Since January 1996, detailed data of perioperative complications occurring during the operation until patients discharge from hospital were available for all patients $(\mathrm{n}=834)$ included in our lung cancer database [15]. General complications like dysfunction of the cardio-pulmonary system, myocardial infarction, dysrhythmia, pulmonary embolism, renal or liver failure, central nervous dysfunction, sepsis, pneumonia and postoperative bleeding requiring blood transfusion were recorded. Empyema, bronchopleural fistula, pneumothorax, chylothorax, wound infection, atelectasis or prolonged air leak, leading to an operative revision were generally classified as specific complications.

Validity of data was assessed by comparing the four groups according to the distributions of main prognostic variables influencing long-term survival, morbidity and mortality in lung cancer patients (age, gender, TNM status, grading, completeness of resection status, treatment and histopathology).

Statistical significance was evaluated using multiple logistic regression analysis [16]. Rates and proportions analyzes were performed using the Chi-square $\left(\chi^{2}\right)$ test. An univariate survival analysis for each prognostic variable on overall survival was estimated according to the Kaplan-Meier method [17] including 95\% confidence intervals [18]. The terminal event was death attributable to all causes. The statistical significance of the differences in survival distributions among the prognostic groups was evaluated by the log-rank test. The statistical difference was considered to be significant if the $\mathrm{P}$ value was below 0.05. Data were analyzed using MedCalc ${ }^{\circledR}$ for Windows, Version 9.2.0.1 (MedCalc Software, Mariakerke, Belgium).

\section{RESULTS}

With respect to the lunar cycle, there were no significant differences in the distribution of TNM-Status (P $=.739)$, grading $(\mathrm{P}=.488)$, completeness of resection $(\mathrm{P}=.638)$, age $(\mathrm{P}=.706)$, gender $(\mathrm{P}=.273)$, treatment $(\mathrm{P}=.797)$ and histopathology $(\mathrm{P}=.466)$. Rate of intraoperative complications was $1.7 \%$, whereas the rate of postoperative complications needing invasive or prolonged treatment was $16.4 \%$. The 30 -day mortality rate was $3.2 \%$. Overall median survival was 28.7 months with a survival rate of $36.0 \%$ at five years. In contrast to age, gender, tumour stage, histopathology, grading and completeness of resection, which have been identified to be independent predictors affecting long-term survival significantly (Table 1), timing of surgery with respect to the moon phases showed no significant impact on long-term survival (Table 2).

Lunar phases showed neither influence on intraoperative complications rate, nor on overall morbidity or mortality. However, as shown in Table 2, also allocation of patients to single days of lunar cycle as well as allocation to waning and waxing phases revealed no significant impact on surgical outcome.

Table 1. Impact of several oncological factors on long-term survival in our cohort.

\begin{tabular}{lllr}
\hline outcome parameter & test used & independent factor & P value \\
\hline Survival & log-rank & T status & $<0.001$ \\
& log-rank & N status & $<0.001$ \\
& log-rank & M status & $<0.001$ \\
log-rank & tumour grading & 0.015 \\
& log-rank & completeness of resection & $<0.001$ \\
& log-rank & pathohistology & 0.003 \\
\hline
\end{tabular}

Table 2. Impact of lunar cycle on intra- and postoperative morbidity, mortality and long-term survival. Outcome parameters are not significantly affected by moon phase.

\begin{tabular}{|c|c|c|c|c|c|}
\hline \multirow[t]{2}{*}{ outcome parameter } & \multirow[t]{2}{*}{ test used } & \multicolumn{3}{|c|}{ independent factor } & \multirow[b]{2}{*}{$\begin{array}{l}\text { full moon } \\
\text { vs. remaining phases }\end{array}$} \\
\hline & & $\begin{array}{l}\text { day of lunar cycle } \\
\text { vs. each other }\end{array}$ & $\begin{array}{l}4 \text { moon phases } \\
\text { vs. each other }\end{array}$ & $\begin{array}{l}\text { waxing } \\
\text { vs. waning moon }\end{array}$ & \\
\hline Survival & log-rank & $\mathrm{P}=.459$ & $P=.646$ & $\mathrm{P}=.631$ & $\mathrm{P}=.110$ \\
\hline operative complications & $\chi^{2}$ & $\mathrm{P}=.963$ & $\mathrm{P}=.430$ & $\mathrm{P}=.579$ & $\mathrm{P}=.941$ \\
\hline post-OP mortality & $\chi^{2}$ & $\mathrm{P}=.885$ & $\mathrm{P}=.952$ & $\mathrm{P}=.756$ & $\mathrm{P}=.920$ \\
\hline post-OP morbidity & $\chi^{2}$ & $\mathrm{P}=.846$ & $\mathrm{P}=.910$ & $\mathrm{P}=.967$ & $\mathrm{P}=.970$ \\
\hline
\end{tabular}




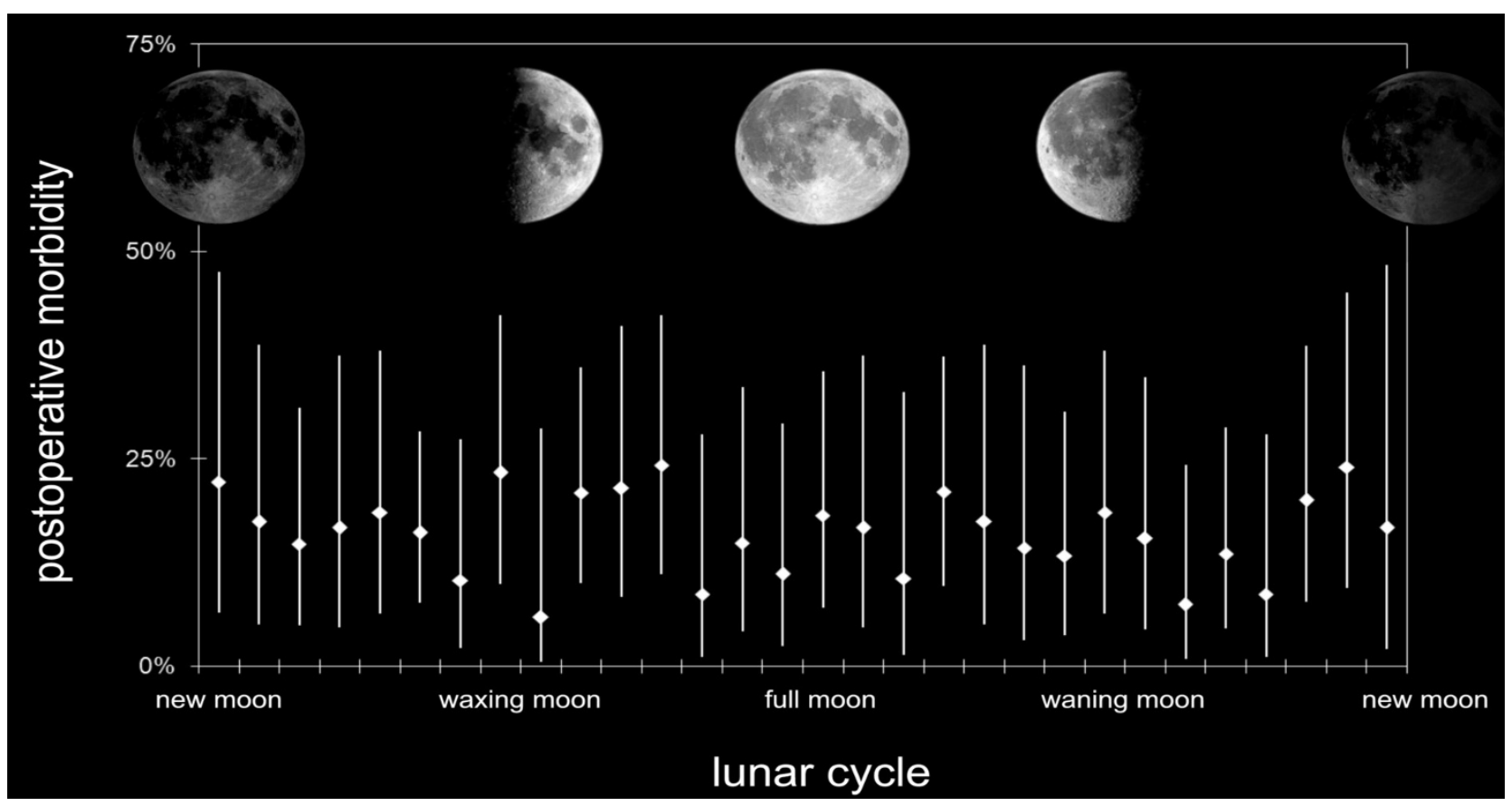

Fig. 1. Rate of postoperative complications in $\%$ on each day of the lunar cycle when initial surgery took place. Rhombi indicate means of morbidity, whereas vertical lines show 95\% CIs. Broad overlapping CIs indicate that there was no statistical difference between each day of lunar cycle (Chi-Square test: $\mathrm{P}=.846)$.

\section{Discussion}

This study revealed that moon phases had generally no measurable impact on outcome after surgery for lung cancer.

In accordance to our results, Peters-Engl and colleagues [4], reporting their results on outcome of 3757 women operated for breast cancer, revealed no effect of moon phases on surgical or patient outcome. Arliss et al. [2] examined the influence of the lunar cycle on the frequency of deliveries and delivery related complications, but also failed to demonstrate predictable influence of moon phases on patients included in the study. In addition, Kumar et al. [13] report about missing evidence that full moon have significant influence on post-tonsillectomy haemorrhage. Postoperative mortality with respect to moon phases was analyzed by Smolle and coworkers [3], but they also failed to demonstrate an impact of lunar phases on outcome. According to these and other studies [1], there was no evidence in our series, that long-term survival was different in any of the four primary moon phases. The overall median survival in this study was 29 months with a 5 -year survival of $36 \%$, which is comparable to international reported survival rates after pulmonary resection for cancer $[19,20]$.

Román and associates [10] described that hospital admission for gastrointestinal bleeding was significantly increased during full moon. In our series postoperative bleeding events were not significantly more frequent during the full moon. To our opinion, this is due to the circumstance, that in the series described by Román et al. the bleeding event was definitively during full moon, in contrast to our study, where bleeding events were always linked to the moon phase at the time of surgery.
Implications for General and Clinical Practice

In this study there was no evidence that outcome of surgery for lung cancer is affected by the moon. These results may help the physician to quite the mind of patients who are somewhat afraid of wrong timing of surgery with respect to the moon phases. On the other hand, locus of control is a well known individual factor within the coping strategies of many patients being in such desperate situations. In whatever these patients trust (internal LOC, powerful other's LOC or chance external LOC), it may supports them handling their disease.

Therefore, patients who strongly believe in the impact of moon phase should be taken seriously and correct timing of operations should be conceded to them as long as key-date scheduling doesn't constrict evidence based treatment regimens.

\section{REFERENCES}

1. Holzheimer RG, Nitz C, Gresser U. Lunar phase does not influence surgical quality. Eur J Med Res 2003; 8: 414-418.

2. Arliss JM, Kaplan EN, Galvin SL. The effect of the lunar cycle on frequency of births and birth complications. Am J Obs Gyn 2004; 192: 1462-1464.

3. Smolle J, Prause G, Kerl H. A double-blind, controlled clinical trial of homeopathy and an analysis of lunar phases and postoperative outcome. Arch Dermatol 1998; 134(11): 1368-1270.

4. Peters-Engl C, Frank W, Kerschbaum F, Denison U, Medl M, Sevelda P. Lunar phases and survival of breast cancer patients - a statistical analysis of 3757 cases. Breast Canc Res Treat 2001; 70: 131-135.

5. Alves DW, Allegra JR, Cochrane DG, Cable G. Effect of lunar cycle on temporal variation in cardiopulmonary arrest in seven emergency departments during 11 years. Eur J Emergency Med 2003; 10: 225-228. 
6. Zimecki M. The lunar cycle: effects on human and animal behavior and physiology. Postepy Hig Med Dosw 2006; 60: 1-7.

7. Culver R, Rotton J, Kelly IW. Geophysical variables and behavior: XLIX. Moon mechanisms and myths: a critical appraisal of explanations of purported lunar effects on human behavior. Psychol Rep 1988; 62: 683-710.

8. Chapman S, Morrell S. Barking mad? Another lunatic hypothesis bites the dust. BMJ 2000; 321: 1561-1563.

9. Neal RD, Colledge M. The effect of the full moon on general practice consultation rates. Family Practice 2000; 17(6): 472-474.

10. Román EV, Soriano G, Fuentes M, Gálvanez ML, Fernández $\mathrm{C}$. The influence of the full moon on the number of admission related to gastrointestinal bleeding. Int $\mathrm{J}$ Nurs Prac 2004; 10: 292-296.

11. Sok M, Miulecky M, Erzen J. Onset of spontaneus pneumothorax and the synodic lunar cycle. Medical Hypotheses 2001; 57(5): 638-641.

12. Eisenburger P, Schreiber W, Vergeiner G, Sterz F, Holzer M, Herkner H, Havel C, Laggner AN. Lunar phases are not related to the occurence of acute myocardial infarction and sudden death. Resuscitation 2002; 56: 187-189.

13. Kumar VV, Kumar NV, Isaacson G. Superstition and post-tonsillectomy hemorrhage. Laryngoscope 2004; 114 : 2031-2033.

14. Moore P, Hunt G, Nicolson I, Chapman S. The atlas of the solar system. London:Mitchel Beazley Publishers 1983;

15. Kuehnl A, Hocaoglu Y, Herzog M, Schmidt M, Hornung HM, Jauch KW, Hatz R, Graeb C. The University of Munich Lung Cancer Group Database: Design, Profile of Cohort and Outcome Analysis. Eur J Med Res 2007; 12(10): 520-526.
16. Cox DR. Regression models and life-table. J R Stat Soc 1972; 334: 187-220.

17. Kaplan EM, Maineri P. Non-parametric estimation for incomplete observations. J Am Stat Ass 1958; 53: 457-481.

18. Greenwood M. The errors of sampling of the survivorship tables. Reports on Public Health and Statistical Subjects 1926; 33: 1-26.

19. Gärtner V, Albes J, Brugger W, Budach W, Duda S, Friedel G, Hruska D, Sökler M, Uckmann FP. Bronchialkarzinom - Empfehlungen zur Diagnostik, Therapie und Nachsorge Südwestdeutsches Tumorzentrum Tübingen 1999; 2: 1-27.

20. Mina K, Byrne MJ, Ryan G, Fritschi L, Newman M, Joseph D, Harper C, Bayliss E, Kolybaba M, Jamrozik K. Surgical Management of lung cancer in Western Australia in 1996 and its outcomes. ANZ J Surg 2004; 74: 10761081.

Received: July 25, 2008 / Accepted: September 26, 2008

Address for correspondence:

PD Dr. med. Christian Graeb

Chirurgische Klinik und Poliklinik Großhadern

Ludwig-Maximilians Universität München

Marchioninistraße 15

81377 München

Germany

Tel.: $\quad+4989 / 70953510$

Fax: $\quad+4989 / 70953508$

E-mail: christian.graeb@med.uni-muenchen.de 